WIENER SLAVISTISCHES JAHRBUCH, Band 56/2010, 109-119

(C) 2010 by Österreichische Akademie der Wissenschaften, Wien

GERHARD NEWEKLOWSKY

\title{
Dalmatien zwischen Čakavisch und Štokavisch: am Beispiel von Bartol Kašić ${ }^{1}$
}

\section{Die KROATISChE KÜSTE}

Nach der Landnahme der Balkanhalbinsel durch die Slaven nach 600 lebten diese an der heutigen kroatischen Küste vermischt mit anderen Völkern, unter denen sich die Romanen, die als Dalmaten bezeichnet werden, am längsten erhielten. Die bekanntesten Episoden, die aus dem Leben des Dalmatischen belegt sind, sind die offizielle Aufgabe der dalmatischen Sprache in Ragusa-Dubrovnik im 14. Jh. und die Aufzeichnung der Sprache des letzten Dalmatisch-Sprechers der Insel VegliaKrk im 19. Jh. Man kann allerdings nicht von einer einheitlichen dalmatischen Sprache ausgehen, sondern muss mehrere Varianten (oder Sprachen) annehmen. Dies waren aber nicht die einzigen Kontakte mit dem Romanischen, sondern es sind auch das Venezianische und das Italienische beteiligt gewesen, außerdem Varietäten des Rumänischen, die durch Wanderhirten Verbreitung fanden. Das Istrorumänische lebt heute noch fort und zumindest der Name der rumänischen Wanderhirten, Vlah (Walache), hat auch in Dalmatien Spuren hinterlassen. Dieser Name konnte durchaus auch für Kroaten gebraucht werden, denn er kann sich außer auf die Religion (Orthodoxe) und auf die romanische Sprache auch auf die Lebensform (Hirten) beziehen. So gibt es beispielsweise unter den Kroaten des Burgenlandes ebenfalls eine Gruppe, die Vlahi genannt wird (ihr Wohngebiet ist die „Vlahija“"). Ihre Herkunft ist bis heute nicht genau geklärt, jedenfalls unterscheiden (bzw. unterschieden) sie sich von anderen Kroaten dieses Gebiets durch ihre Lebensform als Viehzüchter und Hirten, im Gegensatz zu den Acker- und Weinbauern.

${ }^{1}$ Der Text wurde im Oktober 2003 auf der Tagung „Dalmatien als Raum europäischer Kultursynthese", organisiert von Wilfried Potthoff, an der Universität Bonn vorgetragen. Er wird hier - in aktualisierter Form - erstmals veröffentlicht. 
Das Territorium Dalmatiens hat sich im Laufe der Jahrhunderte gewandelt: es war als römische Provinz Teil Illyricums, später Teil des Ostgotenreiches, dann byzantinisches Thema, das zur Zeit der kroatischen Könige Kroatien angeschlossen wurde. Teile der Küste unterstanden zeitweise serbischen Gaufürsten. Unter der ungarischen Herrschaft weiteten sich Begriff und Territorium Dalmatien aus. Später war Dalmatien venezianische Provinz, 1797 wurde es österreichisch, kurzzeitig unter Napoleon Teil Frankreichs, bis nach dem Wiener Kongress 1815 Dalmatien, Dubrovnik und die Bucht von Cattaro-Kotor (Venezianisch Albanien) geeint als Kronland Dalmatien der Österreichischen Reichshälfte der Habsburger Monarchie einverleibt wurden, während Kroatien mit den nördlicheren Teilen der Küste ja der ungarischen Reichshälfte angehörte. Nach dem Ersten Weltkrieg wurde die Küste zwischen Kroatien und Montenegro, das die Bucht von Kotor erhielt, aufgeteilt. Seither ist Dalmatien ein historischer Begriff, unter dem man gewöhnlich das österreichische Kronland Dalmatien versteht, den schmalen Küstenstreifen von der Insel Rab und der Stadt Zadar südwärts bis einschließlich die Bucht von Kotor.

Bald nach der Entstehung der altkirchenslavischen Sprache im 9. Jahrhundert bildete sich in Istrien, auf den Kvarnerinseln und den angrenzenden Gebieten des Festlandes ein Zentrum des slavischen Schrifttums in glagolitischer Schrift heraus, das 1252 durch ein Schreiben des Papstes Innozenz IV. an die Benediktiner von Krk gefestigt wurde. Die Sprache dieses Schrifttums ist einerseits der kroatische Typ des Altkirchenslavischen, andererseits die kroatische Volkssprache, die bereits deutliche Züge des čakavischen Dialekts ikavisch-ekavischer Prägung zeigt. Unter den bekanntesten Texten seien genannt: die Steinplatte von Baška (Krk) (um 1100) und das Gesetzbuch von Vinodol (13. Jh.). Ab dem 14. Jh. beginnt in Dalmatien die Lateinschrift vorzudringen, und es entwickeln sich weitere Sprachformen, die wir als „Landschaftssprachen“ bezeichnen, und zwar der čakavische, ikavische Dialekt mit Vertretern wie Petar Hektorović, Hanibal Lucić oder Marko Marulić ab dem 16. Jh. und dann der štokavische Ostherzegovinadialekt ragusanischer Ausprägung mit seinem herausragenden Vertreter Ivan Gundulić im 17. Jh.

\section{Die DialekTe}

Der Entstehung der verschiedenen Landschaftssprachen lagen die Volksdialekte zugrunde. Heute wird in der nördlichen Hälfte der kroatischen Küste Čakavisch, im Süden Štokavisch gesprochen. Beide Dialekte sind keineswegs in sich einheitlich. Im Norden, in Istrien, auf den Kvarnerinseln und auf dem Festland zwischen Rijeka und Novi Vinodolski wird der čakavische, ikavisch-ekavische Dialekt und weiter südlich mit dem Zentrum Split bis zur Halbinsel Pelješac und auf den Inseln bis Korčula der čakavisch-ikavische Dialekt gesprochen. Die Insel Mljet gehört bereits zum štokavischen Dialektgebiet, das sich nach Süden bis zur albanischen Grenze erstreckt. Dieses letztere Gebiet teilt sich in den neuštokavisch-jekavischen und den altštokavisch-jekavischen Dialekt. Das Zentrum des ersten ist Dubrovnik, während der zweite in Montenegro beheimatet ist. Im dalmatinischen Hinterland, stellenweise 
bis an die Küste reichend, und in der westlichen Herzegovina ist der neuštokavische ikavische Dialekt verbreitet. Die Verteilung der Dialekte und ihre Merkmale sind uns gut aus der kroatischen (und serbischen) Dialektologie bekannt (vgl. die Dialektkarten in Ivić 1958, Moguš 1973, Lisac 2003: 160 f.).

Mit dem Ende des 14. Jhs. und den darauf folgenden Jahrhunderten wurde der größte Teil der Balkanhalbinsel durch die Türken erobert, was im 15. und 16. Jh. gewaltige Bevölkerungsverschiebungen auslöste. Die größten Gebietsverluste erlitt der čakavische Dialekt, während sich die neuštokavischen Dialekte ausbreiteten. Allerdings waren von den Gebietsverlusten die Küstengebiete, wo wir auch heute noch meist alteingesessene Bevölkerung vorfinden, weniger betroffen, wohl aber das dalmatinische Hinterland. (Zur Rekonstruktion der Dialektverhältnisse vor den großen Wanderungen s. Brozović 1967-69: Karten, Lisac 2003: 164 f.)

\section{BARTOL KAŠIĆ}

Eine der bedeutendsten Gestalten der kroatischen Kulturgeschichte ist der Jesuit Bartol Kašić (Bartholomaeus Cassius), der im Zuge der Gegenreformation nicht nur die erste kroatische Grammatik verfasste, sondern auch in seinen späteren Werken die Grundlagen für eine überregionale kroatische, štokavische Schriftsprache legte. Die Reformation blieb bei den Kroaten eine Episode; sie war eng mit der slowenischen Reformation um Primož Trubar und seine Tätigkeit im Württembergischen Exil verbunden. Den Slowenen brachte sie die Schriftsprache mit Trubars Katechismus von 1550, der Bibelübersetzung von Jurij Dalmatin und der ersten slowenischen Grammatik von Adam Bohorič, beide 1574. Ob die kroatischen Werke von Stjepan Konzul und Antun Dalmata, deren Sprache der čakavische Dialekt war und die in Urach bei Tübingen gedruckt wurden, Kašić bekannt waren, entzieht sich unserer Kenntnis. Gabrić-Bagarić (1984: 139-143) führt an, dass der protestantische Usus, Synonyme zur Überwindung der Dialektschranken anzuführen, nur bei Kašić fortgesetzt werde, bei anderen Autoren komme dies nur ausnahmsweise vor. Vorbild für die kroatischen Protestanten war jedenfalls Trubar.

Bartol Kašić wurde 1575 in der Stadt Pag auf der gleichnamigen Insel geboren und lebte dort, unterbrochen von Aufenthalten in Zadar zum Zweck seiner Schulbildung, bis zu seinem 16. Lebensjahr. Dann sandte man ihn auf das Collegium illyricum der Jesuiten nach Loreto und, als dieses 1593 geschlossen wurde, ins Priesterseminar nach Rom, wo er als Novize in den Jesuitenorden eintrat und nach zweijährigem Noviziat Student und Lehrer am Römischen Collegium wurde. Nachdem er 1606 zum Priester geweiht worden war, wurde er zur Missionstätigkeit nach Dubrovnik (1609-12), später über Bosnien nach Belgrad und dann wieder nach Dubrovnik (1613) gesandt. Dann war er kroatischer Beichtvater in Loreto (1614-18), woran sich seine zweite Missionsreise (1618-19) schloss. 1620-33 lebte er wieder in Dubrovnik, und die letzten Jahre seines Lebens, immer im Auftrag seines Ordens, verbrachte er in Rom, wo er 1650 starb. Über sein Leben sind wir durch seine Autobiographie bis 1625 (Vanino 1940, Sršan 1999) und durch spätere Forschungen gut un- 
terrichtet (Horvat 2004: 15-38, Gabrić-Bagarić 2002: 385-389, beide mit ausführlicher Bibliographie).

In Rom verfasste Kašić den kurzen kroatisch-lateinischen „Sprachführer“ und das kroatisch-italienische Wörterbuch (erstmals veröffentlicht in Horvat 1990). Kašić war schon während seiner Studienzeit Lehrer der Grammatik und erhielt 1599 den Auftrag, eine kroatische Grammatik zu schreiben (Vanino 1940: 25, Sršan 1999: 38). Als Ergebnis dieses Auftrags erschien 1604 die älteste kroatische Grammatik Institutionum linguae illyricae libri duo. Es ist bemerkenswert, dass die Grammatik nicht die Beschreibung seines Heimatdialekts der Insel Pag war, sondern die eines überregionalen čakavisch-ikavischen Idioms mit paralleler Berücksichtigung štokavischer Merkmale. Das Ziel der Grammatik war es, als Hilfsmittel für die Mission unter den Balkanslaven zu dienen und so musste er die Sprache breiterer Bevölkerungskreise beschreiben. Man kann annehmen, dass Kašić mit anderen kroatischen Dialekten zunächst in Zadar und dann durch Landsleute in Loreto und Rom in mündlichen Kontakt gekommen war, aber dass er auch Zugang zu kroatischen Büchern hatte.

Die Heimat Kašićs, die Insel Pag, gehört heute mit Ausnahme ihres östlichsten Teils zum čakavischen Dialektgebiet mit ikavisch-ekavischer Vertretung des Jat (Jakić-Cestarić 1957, Finka 1974: 111, Houtzagers 1987: 70 ff.). Umso erstaunlicher ist die Konsequenz, mit der das Ikavische in der Grammatik vertreten ist, es gibt insgesamt nur vier Abweichungen (devojka, peteh, venčac, retko), während alle Beispiele, die in den ikavisch-ekavischen Dialekten $e$ aufweisen, bei Kašić $i$ haben (Neweklowsky 1979: 58). Die Sprache der Grammatik ist schon mehrmals ausführlich beschrieben worden (Šrepel 1890, Gabrić-Bagarić 1976, Neweklowsky 1979, Katičić 1981). Es seien hier nur einige charakteristische Merkmale angeführt: die typische Vertretung des schwachen Jerlautes (zali, vazeti, s manom), $r a>r e$ in restem (aber kradem), $j$ für altes dj (meju, zijem zu zidati), $r$ in morem (neben možem/mogu), die Form človik, zahlreiche Beispiele aus dem Wortschatz usw. Die Morphologie ist typisch čakavisch, daneben werden aber die štokavischen Formen ebenfalls angeführt (auf die štokavische Orientierung wird besonders in Katičić 1981 hingewiesen, s. auch Gabrić-Bagarić 1984, wo die Formen in der Grammatik den Formen in den späteren Werken gegenübergestellt werden). Die ikavische Vertretung des Jat ist den čakavischen wie auch den štokavischen Dialekten Dalmatiens und eines großen Teils Bosniens und der Herzegovina gemeinsam.

Die Grammatik ist vollständig akzentuiert. Kašić gebraucht nach griechischem Vorbild drei Akzentzeichen, den Gravis (') auf kurzen Vokalen und den Akut (') sowie den Zirkumflex $\left(^{\wedge}\right)$ auf langen. Dieses System würde ein typisch čakavisches Akzentsystem mit Intonationsoppositionen auf langen Vokalen, wie es uns auch heute aus zahlreichen čakavischen Dialekten bekannt ist, suggerieren. Ich habe jedoch anderswo (Neweklowsky 1979: 59 ff., 1990: 172 f.) argumentiert, nicht zuletzt auch aus statistischen Gründen, dass es sich hier um ein Zweiakzentsystem ohne Intonationsoppositionen handeln könnte (das Zeichen ' ist gut zehnmal häufiger als 
das Zeichen ${ }^{\wedge}$ ), wie es auch heute auf Pag gesprochen wird (s. auch Kapović 2006: 30). In einer Reihe von Beispielen dienen die Akzentzeichen dazu, um Homonyme zu unterscheiden, was schon von Šrepel festgestellt wurde, z. B. G. pl. sfih : Abl. pl. $s f i h$ (Šrepel 1890: 187) u. ä. Bei folgenden Wörtern, die im Čakavischen fallende Intonation haben sollten, finden wir einerseits Akut wie in clán (član, Institutiones: 10), méfo (12), súnçe (sunce, 33), andererseits Zirkumflex wie in têg, snîg, Bôg, Dûh (29), pûx (puž, 30), tîlo (35) usw. Bezüglich der Akzentstelle handelt es sich um ein System, in dem der Akzent von der offenen betonten Ultima auf einen vorhergehenden langen Vokal zurückgezogen wird, also um ein System mit partieller Akzentverschiebung, z. B. mûka „farina“ (9), gláva (11), zíma (13), mliko (35), slûga (36), glávae (180), rúkce (181), usw. In wenigen Beispielen kann man auch mit einer Akzentverschiebung von einer geschlossenen Silbe rechnen, z. B. sagríscih u. ä. (Kapović 2006: 30). Sonst wird die alte Akzentstelle bewahrt, z. B. zemglià (zemlja) : zèmgli, zèmgliu (11), xenà (žena, 13), hochiù (hoću) : hòchief (hoćeš, 14), petàk (pētäk, 29) usw. Aus den Beispielen erkennen wir, dass der verschobene Akzent auf langen Vokalen in einigen Beispielen mit ', in anderen mit ${ }^{\wedge}$ bezeichnet wird. (Im Übrigen scheint es keine čakavischen Dialekte zu geben, in denen auf der Ultima Neoakut auftritt und gleichzeitig der Akzent von der letzten Silbe verlagert wird.) Gelegentlich wird die Doppelschreibung des Konsonanten angewandt (occe = öče, 31), nebbo (23), um den davor liegenden Iktus zu bezeichnen, selten kommt Doppelschreibung des betonten langen Vokals vor (xenee = ženê G. sg., 9), manchmal gibt es auch konkurrierende Kennzeichnungen innerhalb eines Wortes, wenn Akzentstelle und unbetonte Länge gleichzeitig bezeichnet werden sollen (veccér $=$ vëčèr, 12, jùnáce = jünāče, 31) u. a. (Einzelheiten in Neweklowsky 1979: 60 f., 1981: 28 f.). Katičić (1981: 33 f.) ist der Meinung, dass es trotz allem Regelmäßigkeiten in der Verteilung der beiden Zeichen, und zwar nach morphologischen Kategorien, gebe. Bemerkenswert ist, dass Kašić auch die nachtonigen Längen richtig bezeichnet, obwohl sie in seinem Heimatdialekt (heute) nicht vorkommen. Finka meint, dass diese Kürzung jung sei, da etwa in Vrgada die posttonische Länge noch vorhanden sei (Finka 1974: 114). Der Verlust der Intonationsopposition hänge mit der Akzentverschiebung zusammen (ebda., 115); dieser Meinung schließe ich mich an.

Im Wörterbuch Slovoslovje dalmatinsko italijansko, in dem die Akzentzeichen wohl nachträglich eingetragen wurden (denn sie hören im Buchstaben $O$ auf und kommen später nur noch vereinzelt vor) finden wir eine archaischere Akzentuation mit Bewahrung der alten Akzentstelle, die gut mit der Akzentuation des Dialekts von Pag übereinstimmt (vgl. Houtzagers 1987: 68: „In general, the old place of the stress has been preserved, and, in the first pretonic syllable, also the old quantities“"). Der Zirkumflex wird hier noch seltener gebraucht als in der Grammatik, anscheinend um Homonyme zu unterscheiden, z. B. Cést $-a-o$,spesso -a -o“ (čest - $a-o$ ), gegen Cêsto „spesso“ (Adverb) und zahlreiche weitere Belege. In anderen Beispielen bezeichnet ${ }^{\wedge}$ die unbetonte Länge wie in Glâvà -aé, Hrânà -aé, Hvâlà -aé, Hvâr -à, Lî̀̀ -à, Mûkà -aé, in wieder anderen Beispielen wird zu diesem Zweck ' ge- 
braucht, z. B. Gúdàç (gudac), Mlikò̀. (Das Zeichen ` bezeichnet sowohl im Wörterbuch als auch in der Grammatik den Iktus.)

Wenn Kašić die Akzentzeichen im Wörterbuch selbst gesetzt hat (so Horvat 1990: XVIII f.), hat er zunächst die Akzentuation seines Heimatdialekts genommen, während in der Grammatik ein jüngeres System mit partieller Akzentverschiebung gebraucht wird. Jedenfalls ist die Akzentuation der beiden Werke nicht völlig identisch - wie in Horvat (1990: XX) behauptet wird.

In Kašićs sprachwissenschaftlicher Formierung spielte Dubrovnik, dessen Sprache er ab 1609 erlebte, eine wichtige Rolle. 1617 veröffentlichte er seine Pjesni duhovne, eine Nachdichtung der ersten fünfzig Psalmen. Der Einfluss des štokavischen Dubrovnik äußert sich im häufigen Gebrauch der Endung - $a$ im G. pl., in jekavischen Formen, die neben ikavischen Formen auftreten, aber auch in der Akzentuation. Das Zeichen ^ ist nun praktisch verschwunden, es werden viel häufiger Doppelbuchstaben gebraucht als früher, und die Verwendung der prosodischen Kennzeichnungen ist inkonsequent, Einflüsse der štokavischen Akzentuation sind erkennbar, z. B. cóviek (čovjek, XI, Vorwort) aber clovik (2, u. a.), ferner die jekavische Vertretung des Jat, z. B. od zlòbnijkà gréfcnieh (grešnijeh, 3), aber grìhotu (1), grijh (13, 19, 23), vriednimi (III) aber vridne (11), dieviççu (djevicu, 11) aber diviççu (5) (Genaueres in Neweklowsky 1990: 174 f.).

Abweichend von den modernen neuštokavischen Dialekten gibt es bei Kašić, auch wenn er Štokavisch schreibt, keinen Zusammenfall von Dativ, Instrumental und Lokativ im Plural (Gabrić-Bagarić 1984: 83-91). Bei den maskulinen Substantiven überwiegen die kurzen Pluralformen. Gabrić-Bagarić (1984: 83) erklärt letzteres durch seine čakavische Herkunft. (Dennoch sind Formen mit -ov- vorhanden, siehe unten.) $\mathrm{Zu}$ seiner Zeit gab es allerdings auch in den neuštokavischen Dialekten noch keinen vollständigen Synkretismus der drei Kasus im Plural; er hat sich zwischen dem 16. und 18. Jahrhundert herausgebildet (Belić 1999: 195-202). Einige Beispiele für Pluralformen aus den Pjesni duhovne: vuuke (34), vòlovve (26), vrággove (28), nà vrátieh (30), ùbozzim D. pl. (30), Zlòcinczem D. pl. (21), slúgam D. pl. (32), meyu vriednimi (203), Gorkimi ... Juzàmma I. pl. (19), zúbima I. pl. (32), pijfnima I. pl. (23), Nà nebbefiéh (207), nà graniczczàh (2). Hier fällt auf, dass im Instrumental die neuštokavischen Endungen -ima, -ama (die auch in den Institutiones angeführt werden) bereits vorhanden sind.

Den von Martin Luther stammenden Grundsatz der protestantischen Reformation, in der Volkssprache zu schreiben, und dem folgend Trubar und seine Nachfolger ihre slowenischen Werke im 16. Jh. schrieben, machte sich auch die katholische Gegenreformation zu Eigen, nämlich dass in den Ländern der katholischen Missionierung die am weitesten verbreitete Volkssprache zu verwenden sei. Der Sprache des kroatischen Protestantismus war kein Erfolg beschieden, man wusste über die sprachlichen Verhältnisse auf der Balkanhalbinsel nicht Bescheid. Die Hilfe der štokavischen, uskokischen Priester, die zeitweise in der Uracher Bibelanstalt Trubars mitarbeiteten, war oft eher eine Belastung, und so blieb die sprachliche Grundlage 
der kroatischen protestantischen Bücher ein čakavischer Dialekt mit geringer Verbreitung, während Trubar andererseits der Meinung war, das Čakavische werde von den Kroaten, Dalmatinern, Bosniern, Serben und Bulgaren verstanden, auch wenn es gewisse Unterschiede im Wortschatz und in der Schrift gebe (z. B. im Vorwort zum glagolitisch gedruckten Ersten Teil des kroatischen Neuen Testaments von 1562, Sakrausky 1989: 219).

Die offizielle Haltung der katholischen Kirche gegenüber der Sprache in den katholischen ,illyrischen“ Gebieten entstand nach der Gründung der Sacra Congregatio de propaganda fide 1622, als Enqueten unter den kroatischen Bischöfen zur Erhebung der sprachlichen Situation durchgeführt wurden. Das Ergebnis war, dass als am weitesten verbreitete Sprache das „Bosnische“ angesehen wurde, die Sprachform, die Kašić durch die Berücksichtigung des Štokavischen bereits in seiner Grammatik 1604 verwendet und 1613 auf seiner Missionsreise kennengelernt hatte (vgl. Švelec 1994).

Etwa zur gleichen Zeit scheint sich Kašić an die Übersetzung der Heiligen Schrift gemacht zu haben (Horvat 1992: 6 im Nachwort des Ritual rimski, Katičić 1999: 60). Die Unzulänglichkeiten der vorhandenen Übersetzungen veranlassten die Congregatio 1625, dem Ragusaner Erzbischof anzuordnen, dass er Kašić beauftrage, die Bibel zu übersetzen. Diesem Auftrag kam Kašić in Dubrovnik und Rom nach; er war spätestens 1636 abgeschlossen. Durch eigene Landsleute wurde die Veröffentlichung allerdings verhindert (Horvat 1992: 7). Die Übersetzung ist in einem lang dauernden Prozess entstanden, der schon vor der offiziellen Beauftragung begann (Horvat 2004: 154-159). Die kürzlich veröffentlichten Dokumente lassen den Schluss zu, dass die kroatische Sprache selbst (Volkssprache statt Kirchenslavisch) und das lateinische Alphabet die Veröffentlichung behinderten, da man noch immer mit einer Union mit den Orthodoxen rechnete (Erdmann-Pandžić 1999).

Trotz dieses Misserfolgs machte sich Kašić an einen neuen, 1634 gestellten Auftrag (ebda., 119 f.), nämlich die Übersetzung des Rituale romanum, erschienen 1640, dessen Vorwort schon mit 1636 datiert ist. Dort erfahren wir über die Sprache, die ,illyrica lingua“ genannt wird, dass der Verfasser jene Sprache verwenden soll, die die allgemeinste ist und die jeder leicht verstehen kann:

Ovim dakle nacinnom odlùcih yà Pijfmo ovega Rituala, illi Obicàynika iftomacciti nafcki, bivfci yà govorio, $\mathrm{i}$ opcchìo s'gliùdmi od razliçih Rusàgà Slovinskih, hodecchi pò sfijtu: $\mathrm{i}$ yàfam gnih ovakka govorenya razumio, i onifu moya: (Karftyani, Rafciani, Serbgli Poluvirçi, i Turçi.)

Und wenn er folgende Wörter bosnisch schreibe (es folgen Perfektformen des Typs poslao sam), so verbiete er weder dem Dalmatiner noch Ragusaner, die Formen auf ihre Weise auszusprechen (poslal oder posla sam). Das heißt, obwohl Kašić nach einer normierten Schriftsprache strebt, lässt er gewisse Freiheiten in der Stilisierung zu.

Im Vorwort rechtfertigt er sein Alphabet, das den Grundsatz der stets gleichen Aussprache der Buchstaben verfolgt; er zählt auch seine Werke auf, in denen er im- 
mer auf gleiche Weise geschrieben habe, und vorher (im unpaginierten „Blagomu i milomu štiocu“) führt er die Schriftsteller an, die das gleiche Alphabet verwendet haben. Diese Feststellung darf man nicht zu eng sehen, denn im Einzelnen bestehen doch Unterschiede, vor allem in der Doppelschreibung von Buchstaben und in der Setzung der prosodischen Zeichen. Im Ritual rimski verwendet Kašić hauptsächlich den Gravis (') zur Bezeichnung der Akzentstelle, sowohl auf langen als auch auf kurzen Vokalen, aber auch gelegentlich zur Bezeichnung der unbetonten Längen. Freilich könnte dies auf das Konto des Setzers gehen.

Dieses Buch spielte in der Geschichte der kroatischen, štokavischen Schriftsprache eine ganz wichtige Rolle: Es wurde neben den Pištole $i$ evanđelja des Bosniers Ivan Bandulavić durch zweieinhalb Jahrhunderte in fast allen kroatischen Landstrichen gebraucht, wobei es sechs Auflagen erlebte. Die moderne kroatische Schriftsprache kann als Fortsetzerin der Sprache Kašićs gesehen werden (Babić 1994). Hinsichtlich des Jatreflexes sieht man aus Kašićs Werken, was für einen Einfluss die literarische Tradition (Dubrovnik, aber auch die zu seiner Zeit entstehende Literatur der bosnischen Franziskaner) hatte. Ikavisch sind (abgesehen von der Grammatik) nur zwei Werke geschrieben (Život gospodina našeg Isukrsta, Život Marijin), während alle anderen ikavisch/jekavische Reflexe zeigen (Gabrić-Bagarić 1984: 47; siehe auch die tabellarische Aufstellung, 42-45).

Obwohl die Sprache des Rituale romanum zu Lebzeiten Kašićs ungleich wichtiger war als die Sprache seiner Bibelübersetzung, soll doch auf letztere kurz eingegangen werden, weil sie den Werdegang Kašićs mit verfolgen hilft. Katičić (1999: 65) stellt fest:

Seine schriftsprachliche Stilisierung ist zweifellos ein Neubeginn, auf die Zukunft ausgerichtet mit der Bestrebung in die Weite zu wirken und den Ausgangspunkt für solide Volksbildung zu schaffen. Das ist offensichtlich ein Ansatz zum Ausbau einer neuzeitlichen Standardsprache. Kašić redigiert nicht in seiner Bibelübersetzung überlieferte Texte. Er schafft für die Bibel einen neuen kroatischen Ausdruck ... Seine Gestaltung des sprachlichen Ausdrucks richtet sich doch auch nach der Tradition, die durchaus einbezogen wird, wenn sie sich nach dem Empfinden des Übersetzers vorbehaltlos mit der Volkssprache vereinbaren lässt.

Die Sprache der Übersetzung ist štokavisch, ihre wichtigsten Merkmale werden von Katičić (a. a. O.) angeführt: die häufige jekavische Vertretung des Jat, das $u$ aus $v b$ (uzeti), $-l$ wird zu -o (außer in Beispielen wie vol etc.), die östlichen Merkmale -št- (prebivalište) und $d$ (etwas seltener), ebenso die Endung - $a$ im G. pl., nicht aber andere Pluralkasus (was aber damals durchaus auch štokavisch war). Er schreibt der Tradition gemäß das $h$ mit einigen Abweichungen an der richtigen Stelle (im Čakavischen ist es auch heute gut bewahrt). Der Verlust des $h$ hat sich nach Belić (1999: 96 f.) im Štokavischen zwischen dem Ende des 16. und dem 18. Jahrhundert vollzogen (als sich auch die neuštokavischen Endungen in der Pluraldeklination durchsetzten, s. oben).

Die Bibel ist nach ähnlichen Gesichtspunkten wie die Grammatik akzentuiert. Leider wurden die Akzentzeichen des Originals in der Ausgabe 1999 nicht berück- 
sichtigt. Aus den beigefügten Faksimiles des Autographen Kašićs (Bd. 2, 23-40) können jedoch einige Schlüsse gezogen werden: die orthographischen Lösungen sind dieselben wie schon in den Institutiones; die Doppelschreibung von Vokalen dient zur Bezeichnung der betonten Länge (Boog, pijsmo), die Doppelschreibung von Konsonanten zur Bezeichnung des Iktus auf dem vorhergehenden Vokal (boggovi N. pl., recce Aor., od rodda, nogga, Imme), es werden dieselben Akzentzeichen gebraucht. Es scheint, dass auch hier Homonyme gelegentlich durch die Setzung verschiedener Akzentzeichen unterschieden werden, z. B. gnegá (njega) A. sg. : od gnegà (neben od gnegá). Wir finden dieselbe partielle Akzentverlagerung wie in den Institutiones (líjça G. sg., glávae G. sg., iz rúkae) und die Bewahrung der alten Akzentstelle in anderen Positionen (texák = težak Subst., yedàn, otàç, dobrà G. sg., dovedè Aor., glávu A. sg., mésom I. sg., ù pogliu = polju). Im G. pl. stehen häufig zwei Akzentzeichen (górá, od ováçá, od rébarâ), seltener in anderen Fällen (nà dvôr).

Kašić ist hier bei seinem Akzentsystem von 1604 geblieben. Das Ritual rimski unterscheidet sich zwar graphisch, entspricht aber ebenfalls demselben System, wobei genauere Untersuchungen noch nötig sein werden. Dass Kašić nicht das neuštokavische Akzentsystem verwendet, entspricht durchaus den Grundsätzen der Congregatio, sich nämlich einem möglichst großen Kreis von Menschen verständlich zu machen, Čakavern wie Štokavern.

\section{Schluss}

Bartol Kašić ist heute durch eine Reihe von Nachdrucken und Textausgaben der Forschung sehr gut zugänglich. (Nur ein Teil dieser Ausgaben konnte hier berücksichtigt werden.)

Die sprachliche Entwicklung Kašićs ist konsequent. Von allem Anfang an wird das Štokavische berücksichtigt, auch wenn zunächst die Grundlage der Institutiones ein überregionaler čakavisch-ikavischer Dialekt ist. Die Entscheidung für das Ikavische war der gemeinsame Nenner sowohl des Štokavischen wie des Čakavischen. Nach seinen Aufenthalten in Dubrovnik und im Inneren der Balkanhalbinsel dringt das Jekavische in seine Schriften ein, aber nicht ausschließlich. Einzelne čakavische Merkmale bleiben neben den štokavischen Formen bestehen, z. B. človik neben čovik und čovjek.

Die Bewahrung des /h/ dürfte den Stand des neuštokavischen Dialekts im 17. Jh. widerspiegeln; in der Mehrzahl der štokavischen Dialekte geht es erst im Laufe des 17. Jahrhunderts verloren. Ähnliches gilt für die Pluralkasus in der Morphologie. Während der G. pl. auf - $a$ alt ist, hat sich der Synkretismus von Dativ, Instrumental und Lokativ erst zu Kašićs Zeiten ausgebreitet.

Einzig die Akzentuation bleibt ein bisschen rätselhaft. Die neuštokavische Akzentuation besteht seit dem 14. Jahrhundert. Kašić verwendet nicht die altertümliche Akzentuation seines Heimatdialekts, sondern ein etwas jüngeres System mit partieller Akzentverlagerung, das sowohl in štokavischen wie in čakavischen Dialekten auftritt. Einflüsse des neuštokavischen Akzents, den er von seinen Missionsreisen 
und Aufenthalten in Dubrovnik gut kennen musste, sind nur gelegentlich zu beobachten.

\section{Literatur}

Babić 1994:

S. Babić, Jezik ,Rituala rimskoga‘ - važna sastavnica u razvoju hrvatskoga književnog jezika, in: Kolumbić 1994, 95-100

Belić 1999:

А. Белић, Историја српског језика (= Изабрана дела Александра Белића 4), Београд

Brozović 1968-70:

D. Brozović, Dijalekatska slika hrvatskosrpskoga jezičnog prostora, Radovi, Filozofski fakultet Zadar, razdio lingvističko-filološki 8, 5-32 + Karten

Erdmann-Pandžić 1999: E. von Erdmann-Pandžić, Der gescheiterte Drucklegungsversuch der Kašić-Bibel, in: Kašić 1999, 2. Band, 99-129

Finka 1974:

B. Finka, O govorima zadarskog otočja, in: Zbornik Zadarsko otočje; povremena izdanja Narodnog muzeja u Zadru 1, 109-116

Gabrić-Bagarić 1976: D. Gabrić-Bagarić, Institutionum linguae illyricae Bartola Kašića i težnje ka standardizaciji jezika, Književni jezik, 5/1-2, 55-68

Gabrić-Bagarić 1984: D. Gabrić-Bagarić, Jezik Bartola Kašića (= Institut za jezik i književnost u Sarajevu, Institut za jezik, posebna izdanja 5), Sarajevo

Gabrić-Bagarić 2002:

Horvat 1990:

Horvat 1992:

Horvat 2004:

Houtzagers 1987:

Ivić 1958:

D. Gabrić-Bagarić, Pogovor, in: Kašić 1604/2002, 383-445

V. Horvat (ed.), Bartol Kašić SI, Hrvatsko-talijanski rječnik s Konverzacijskim priručnikom (= Bibliofilska izdanja 24), Zagreb

V. Horvat, Pogovor, in: Kašić 1640, 3-22

V. Horvat, Bartol Kašić - otac hrvatskoga jezikoslovlja. 2. izdanje (= Biblioteka CROATICUM 2), Zagreb

H. P. Houtzagers, On the Phonology and Morphology of the Čakavian Dialects Spoken on the Island of Pag. Dutch Studies in South Slavic and Balkan Linguistics (= Studies in Slavic and Balkan Linguistics 10), Amsterdam, 65-90

P. Ivić, Die serbokroatischen Dialekte. Ihre Struktur und Entwicklung. Erster Band: Allgemeines und die štokavische Dialektgruppe (= Slavistic Printings and Reprintings 18 ), s'Gravenhage

Jakić-Cestarić 1957: V. Jakić-Cestarić, Refleks jata na sjeverno-dalmatinskim otocima, Radovi Instituta JAZU u Zadru 3, 407-422

Kapović 2006: $\quad$ M. Kapović, Bilješke o naglasku Kašićeve gramatike, Croatica et Slavica Iadertina 2, 27-41

Kašić 1604/1977: $\quad$ B. Cassius (Kašić), Institutiones linguae illyricae. Nunc iterum edidit R. Olesch, Köln - Wien

Kašić 1604/2002: $\quad$ B. Cassius (Kašić), Institutiones linguae illyricae / Osnove ilirskoga jezika. Prijevod s izvornika: Sanja Perić Gavrančić (= Biblioteka Pretisci 1), Zagreb

Kašić 1617/1978: $\quad$ B. Kašić, Pjesni duhovne. Nachdruck besorgt und eingeleitet von Hans-Joachim Härtel (= Beiträge zur Kenntnis Südosteuropas und des Nahen Orients 27), München

Kašić 1640: $\quad$ B. Kašić, Rituale romanum Urbani VIII. pont. max. iussu editum. Illyrica lingua $($ Nachdruck $=$ Bibliofilska izdanja 26, Posebna izdanja Zavoda za hrvatski jezik 3), Romae

Kašić 1990:

B. Kašić, Hrvatsko-talijanski rječnik s Konverzacijskim priručnikom. Priredio Vladimir Horvat, Zagreb

Kašić 1999:

B. Kašić, Biblia sacra versio illyrica selecta, seu declaratio Vulgatae editionis latinae. Bartholomaei Cassij Curictensis e Societate Iesu professi, ac Sacerdotis theologi. Ex mandato Sacrae Congregationis de propag: Fide. Anno 1625. Band 1: Transkription Petar Bašić, Julije Derossi, Zlata Derossi. Band 2: Kommentare. Wörterverzeichnis, Pa- 
Katičić 1981:

Katičić 1999:

Kolumbić 1994:

Lisac 2003:

Moguš 1977:

Moguš 1993:

Neweklowsky 1979:

Neweklowsky 1981:

Neweklowsky 1990:

Sakrausky 1989:

Sršan 1999:

Šrepel 1890:

Švelec 1994:

Vanino 1940: derborn etc.: Ferdinand Schöningh (= Biblia Slavica, Serie IV: Südslavische Bibeln 2,1 und 2,2)

R. Katičić, Gramatika Bartola Kašića, Rad JAZU, Razred za filologiju $388,5-129$

R. Katičić, Über die Sprache der Kašićschen Bibelübersetzung, in: Kašić 1999, Bd. 2, 59-69

N. Kolumbić (odg. urednik), Život i djelo Bartola Kašića. Zbornik radova (= Izdanja Hrvatskog filološkog društva 5), Zadar

J. Lisac, Hrvatska dijalektologija 1. Hrvatski dijalekti i govori štokavskog narječja i hrvatski govori torlačkog narječja, Zagreb

M. Moguš, Čakavsko narječje. Fonologija, Zagreb

M. Moguš, Povijest hrvatskoga književnoga jezika, Zagreb

G. Neweklowsky, Einige Bemerkungen zur ältesten kroatischen Grammatik, Wiener Slavistisches Jahrbuch 25, 56-62

G. Neweklowsky, ,Граматика илирског језика Бартола Кашића“ из 1604. године, Научни састанак слависта у Вукове дане 10, 25-31

G. Neweklowsky, Zur Akzentuation bei Bartol Kašić, Wiener Slavistisches Jahrbuch, Ergänzungsband VIII. Hsg. Georg Holzer, Wien, $171-176$

O. Sakrausky, Deutsche Vorreden zum slowenischen und kroatischen Reformationswerk (= Studien und Texte zur Kirchengeschichte und Geschichte. Fünfte Reihe, Band 1), Wien

S. Sršan (prijevod), Život Bartola Kašića, Osijek

M. Šrepel, Latinski izvor i ocjena Kašićeve gramatike, Rad JAZU 102, 172-201

F. Svelec, Pitanja jezika i pisma propagandinih izdanja u sklopu Kašićevih jezikoslovnih intencija, in: Kolumbić 1994, 51-60

M. Vanino, Autobiografija Bartola Kašića, Građa za povijest književnosti hrvatske $15,1-144$

A b stra c t: Dalmatia between Čakavian and Štokavian: the example of Bartol Kašić. By the term Dalmatia we understand above all the territory of the former Austrian province of Dalmatia along the Adriatic coast. Two different Croatian dialects are spoken in this region: Čakavian and Stokavian. In order to spread the Catholic faith among the Balkan Slavs the Jesuits assigned Bartol Kašić to write a grammar of the Croatian language. The oldest Croatian grammar of 1604 is essentially a grammar of the Čakavian Ikavian dialect, which was not Kašić's vernacular. It is therefore assumed that he was looking for a common denominator between Čakavian and Stokavian, which could have been the Ikavian dialect with partial accent shift. In his grammar Kašić describes not only the Čakavian, but also the complete Štokavian, morphology. After having lived in Dubrovnik and travelled to the interior of the Balkan peninsula he began to write more and more Štokavian Yekavian including Stokavian morphology as he began to consider the Bosnian language as the most widely spread and most beautiful dialect of Croatian. The article examines Kašić's linguistic development.

K e y w ord s: Dalmatia, Oldest Croatian grammar, Bartol Kašić, forming of the Croatian literary language, 17th century

Gerhard Neweklowsky

Emil Mendegasse 15

9073 Klagenfurt, Österreich

gerhard.neweklowsky@uni-klu.ac.at 
